\title{
Polyethylene-polyaniline Nanofiber Composites: Evaluation of Experimental Conditions of in situ Polymerization
}

\author{
Ana Paula Graebin ${ }^{a}$, Leila Bonnaud ${ }^{b}$, Olivier Persenaire ${ }^{b}$, Oltea Murariu ${ }^{b}$, \\ Philippe Dubois ${ }^{b}$, Zenis Novais da Rocha ${ }^{c}$, Nara Regina de Souza Basso ${ }^{a *}$ \\ ${ }^{a}$ Faculdade de Química, Pontifícia Universidade Católica do Rio Grande do Sul-PUCRS, \\ Av. Ipiranga, 6681, CEP 90619-900, Porto Alegre, RS, Brazil \\ ${ }^{b}$ Laboratory of Polymeric and Composite Materials - LPCM, Center of Innovation and Research in \\ Materials \& Polymers - CIRMAP, University of Mons UMONS \& Materia Nova Research Center, \\ Place du Parc 23, B-7000 Mons, Belgium \\ ${ }^{c}$ Grupo de Pesquisa em Química de Coordenação, Instituto de Química, Universidade Federal da Bahia \\ - UFBA, Campus Universitário de Ondina, Rua Barão de Geremobo, s/n, \\ CEP 40170-115, Salvador, BA, Brazil
}

Received: November 12, 2014; Revised: July 28, 2015

The difficult processability of polyaniline (PAni) can be overcome by preparing composites with high density polyethylene (HDPE), resulting in a conducting material with improved mechanical properties. PAni nanofibers were synthesized in this research using a rapid mixing method, while HDPE/PAni composites were prepared by in situ polymerization using $\mathrm{Cp}_{2} \mathrm{ZrCl}_{2} / \mathrm{MAO}$ as a catalyst system. Different experimental conditions for polymerization and an electrochemical study were performed. The findings confirmed that the addition of small amounts of Pani (up to 7\%) and longer impregnation (120 min) with methylaluminoxane (MAO) before polymerization are important factors contributing to increased catalytic activity. Analysis by cyclic and differential pulse voltammetry indicates that MAO reacts with the PAni in the ethylene polymerization process, and forms active species in the presence of the catalyst. Changes in catalytic activity may be due to the kinetic consumption of the active species, which become less important in the presence of PAni.

Keywords: polyaniline, polyethylene, cyclic voltammetry, composites

\section{Introduction}

Major advances have taken place in recent years in the technological application of conductive polymers thanks to their convenient processability. This has led to developments mainly in microelectronics and sensors, rechargeable batteries, electrochromic displays, light-emitting devices, and photovoltaic and insulation panels ${ }^{1,2}$. Polyaniline (PAni) stands out among the conductive polymers due to its high electrical conductivity, chemical stability under ambient conditions, processability, ease of polymerization and doping ability, combined with low cost and low toxicity ${ }^{3}$. New methodologies have been developed within the past few years for the preparation of PAni-based nanostructures capable of dispersion, such as nanowires, nanofibers and nanotubes ${ }^{4}$.

PAni nanofibers can be prepared by rapid mixing, a simple and fast methodology that presents the advantage of not using organic solvent. However, applications of PAni have been limited due to its low solubility in common organic solvents and its difficult processability. This drawback can be overcome by the dispersion and formation of a conductive network of Pani nanofibers within conventional polymers, following different approaches

*e-mail: nrbass@pucrs.br such as melt blending by extrusion, solution/dispersion, in situ polymerization, and electrochemical polymerization ${ }^{5}$. The principal advantages of these techniques lie in their easy up-scaling ability at relatively low cost. Few studies regarding in situ polymerization of ethylene in the presence of PAni have been reported in the scientific literature. Nonetheless, this method has been successfully applied to several types of particles (organomodified clays, carbon nanotubes, graphene sheets, etc.), leading to a more uniform dispersion of the nanoparticles within different polymer matrices, when compared to the direct dispersion attempts of neat particles ${ }^{6,7}$.

PAni-filled polyethylene (PE/PAni) nanocomposites were successfully prepared by in situ polymerization of ethylene, directly catalyzed in the presence of PAni nanofibers. The catalyst system used was $\left[(\mathrm{Cp})_{2} \mathrm{ZrCl}_{2}\right] / \mathrm{MAO}$. PAni nanofibers were found to significantly affect crystallization of the polyolefinic matrix, while preserving its thermal stability. A rise of catalytic activity by increasing the relative content of nanofibers was also observed. Measurement of the electrical properties showed that the PAni nanofibers were able to bring electro-conductive properties to the in situ polymerized PE/PAni nanocomposites. Such results 
are very promising in the search for new materials for engineering applications that require electrical conductivity ${ }^{8}$.

Cyclic and differential pulse voltammetry were employed in order to investigate the reactivity of $\mathrm{Zr}$ - and Ti alkoxide bidentate complexes in the presence of methylaluminoxane (MAO) and ethylene ${ }^{9,10}$. The catalytic species resulting from the interaction between $\left[\mathrm{Me}_{2} \mathrm{Si}(\mathrm{Cp})_{2} \mathrm{ZrCl}_{2}\right]$ or $\left[\mathrm{Cp}_{2} \mathrm{ZrCl}_{2}\right]$ with MAO or trimethylaluminum (TMA) were also investigated by cyclic voltammetry ${ }^{11}$. Furthermore, a series of metallocenes bearing different coordination spheres (Cp, MeCp, $n$-BuCp, $i$-BuCp, $t$-BuCp, Ind, $\left.\mathrm{IndH}_{4}\right)$, bridges (Et, $\left.\mathrm{Me}_{2} \mathrm{Si}\right)$ and metal centers $(\mathrm{Zr}, \mathrm{Ti}, \mathrm{Hf})$ were comparatively analyzed by voltammetry, and the correlation between electrochemical characteristics and catalysis activity evaluated ${ }^{12-14}$. Therefore, an understanding of the interaction between the $\left[\mathrm{Cp}_{2} \mathrm{ZrCl}_{2}\right] / \mathrm{MAO}$ catalytic system and PAni can be substantiated by making use of pulse differential voltammetry.

PAni nanofibers were prepared in this work by the rapid mixing method and polyethylene composites by means of in situ polymerization. The ethylene polymerization process in the presence of nanofibers was studied through cyclic and differential pulse voltammetry in order to understand the interaction of the $\mathrm{Cp}_{2} \mathrm{ZrCl}_{2} / \mathrm{MAO} / \mathrm{PAni}$ catalytic system.

\section{Experimental}

\subsection{Material}

Aniline (Merck) was distilled in the presence of metallic zinc, as was toluene (F. Maya) with metallic sodium and benzophenone before their use. Ammonium peroxide disulphate (APS), hydrochloric acid (HCI) (Merck), methylaluminoxane (MAO) (10\% by weight in toluene, Aldrich), dichlorobis(cyclopentadienyl)zirconium(IV), and $\left.\left[(\mathrm{Cp})_{2} \mathrm{ZrCl}\right)_{2}\right]$ (Sigma-Aldrich) were used as received. All manipulations for the synthesis of PE/PAni nanocomposites were carried out under an inert atmosphere (nitrogen or argon) using standard Schlenk techniques.

\subsection{Polyaniline nanofibers synthesis}

Polyaniline nanofibers were prepared by rapid mixing synthesis, following the methodology proposed by Huang $\& \mathrm{Kaner}^{15}$. The aniline polymerization was carried out at $60{ }^{\circ} \mathrm{C}$. Ammonium peroxide disulphate (APS) was used as an oxidizing agent and hydrochloric acid (HCI) 1 mol.L $\mathrm{L}^{-1}$ as a dopant agent. The reaction yield was about $21 \%$. In order to improve the removal of moisture and free dopant acid, the PAni nanofibers were washed repeatedly with a solution of water and acetone until $\mathrm{pH} 4$. Then the sample was dried under vacuum in an oven at $80^{\circ} \mathrm{C}$ for 30 hours.

\subsection{PE/PAni nanocomposites synthesis}

The polymerization reactions were carried in a $250 \mathrm{~mL}$ glass reactor. Dried toluene was used as a solvent, MAO as a cocatalyst, and $\left.\left[(\mathrm{Cp})_{2} \mathrm{ZrCl}\right)_{2}\right]$ as a catalyst $\left(5 \times 10^{-6} \mathrm{~mol}\right)$. For all polymerizations, MAO and $\left.\left[(\mathrm{Cp})_{2} \mathrm{ZrCl}\right)_{2}\right]$ were added in such a way that the $[\mathrm{Al}] /[\mathrm{Zr}]$ ratio was 1200 . PAni nanofibers were overnight dried at $50{ }^{\circ} \mathrm{C}$ under reduced pressure (ca. 5 mbars). Before the polymerization stage, dried PAni were sonicated (Unique Ultracleaner 1600A, $40 \mathrm{kHz}$ ) in toluene (20 or $60 \mathrm{~min}$ ). Then a pretreatment was carried out by adding MAO and keeping it under mixing at $50{ }^{\circ} \mathrm{C}$ for a certain period of time (from 30 to 120 minutes). Next, $\left.\left[(\mathrm{Cp})_{2} \mathrm{ZrCl}\right)_{2}\right]$ was added and the mixture kept under stirring for $30 \mathrm{~min}$. The ethylene polymerization were carried out at $50{ }^{\circ} \mathrm{C}$ for 12 minutes by using different ethylene pressure (2.0 or 2.8 bars). After polymerization, the reaction mixture was dispersed in 7 volumes of methanol acidified with few drops of $\mathrm{HCl}$ aqueous solution $\left(1 \mathrm{~mol} . \mathrm{L}^{-1}\right)$ and nanocomposites recovered by filtration.

\subsection{Differential pulse voltammetry (DPV)}

The pulse differential voltammograms were taken with a potentiostat/galvanostat (PARC, model 273). All experiments were carried out using a conventional three electrode cell. Glassy carbon was used as the working electrode and another electrode was built from a PVC body having a graphite disk, which supports a carbon paste. Carbon paste was prepared by mixing high purity graphite $(100 \mathrm{mg})$ (Fisher Scientific) and the polyaniline $(30 \mathrm{mg})$ with a few drops of mineral oil. $\mathrm{An} \mathrm{Ag} / \mathrm{AgCl}$ electrode was used as a reference electrode and a platinum wire as an auxiliary electrode. The $\mathrm{Ag} / \mathrm{AgCl}$ electrode was calibrated with ferrocene, which was used as an internal reference. These measurements versus the ferrocene $\left(\mathrm{Fc}+/ \mathrm{Fc}^{0}\right)$ redox couple $(+0.45 \mathrm{~V}$ in acetonitrile solutions) were reported against an $\mathrm{Ag} / \mathrm{AgCl}$ electrode. Electrochemical data was attained by using 0.1 mol.L $\mathrm{L}^{-1}$ solutions of tetrabutylammonium tetrafluoroborate in acetonitrile as a supporting electrolyte. All solutions were deaerated by bubbling with high purity argon. The cocatalyst solutions were prepared with different $[\mathrm{Al} / \mathrm{Zr}]$, 3 and 6 ratios and the pulse voltammograms were recorded with a scan rate of $100 \mathrm{mV} \cdot \mathrm{s}^{-1}$.

\subsection{Polyaniline nanofibers and composites based on PE/PAni characterization}

Scanning Electron Microscopy (SEM) was carried out with the use of a Hitachi SU8020 model microscope, operating at $1.5 \mathrm{kV}$. Electrical conductivity measurements were carried out on samples in the form of pellets $(13 \mathrm{~mm}$ diameter by $2 \mathrm{~mm}$ thick) using a Keithley Multimeter Multimeter / Switch System Integra Series, Model 2750.

\section{Results and Discussion}

\subsection{Polyaniline nanofiber synthesis}

PAni nanofibers were synthesized via the rapid mixing method, which entails the aniline and oxidizing agent (APS) being mixed rapidly in the presence of the dopant (HCI). All the reagents in this process are considered to be consumed in the initial formation of nanofibers, thus preventing secondary growth that would result in the formation of particulate PAni ${ }^{5,16}$. The main advantage of this procedure over interfacial polymerization is the absence of a solvent as a reagent. A washing step to $\mathrm{pH} 4$ and oven-drying were then carried out to remove 
excess dopant and residual moisture in order to prevent deactivation of the catalyst system during the in situ ethylene polymerization stage ${ }^{8}$.

Typical SEM images of the synthesized PAni nanofibers are shown in Figure 1. Nanofibers characterized by high aspect ratio proved to form a largely interconnected network.

PAni conductivity is dependent on the concentration and mobility of charges (electron migration along the polyaniline chain), which in turn depends on the type of dopant, preparation method and structure of the doped PAni ${ }^{17}$.

Preparation of the PAni nanofibers by the rapid mixing method was found not to have significantly changed the morphology and electrical conductivity of the nanofibers after the pretreatment step, as seen in Figure $1 \mathrm{~b}$ and Table 1.

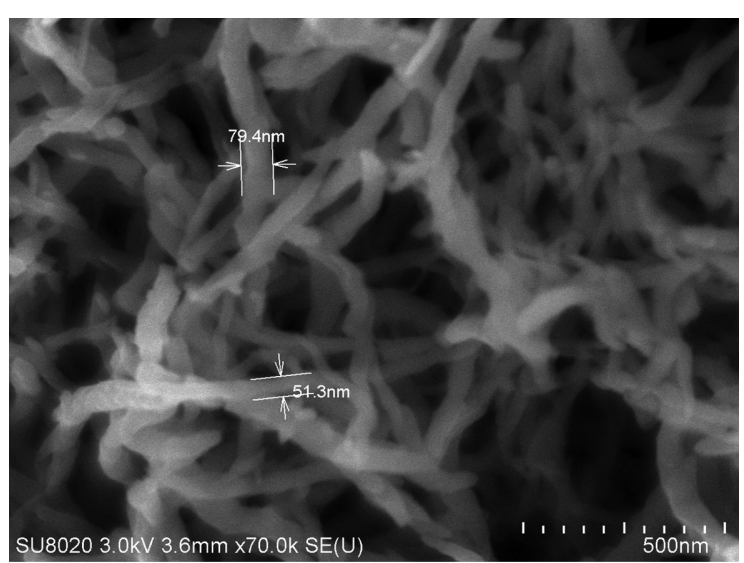

(a)

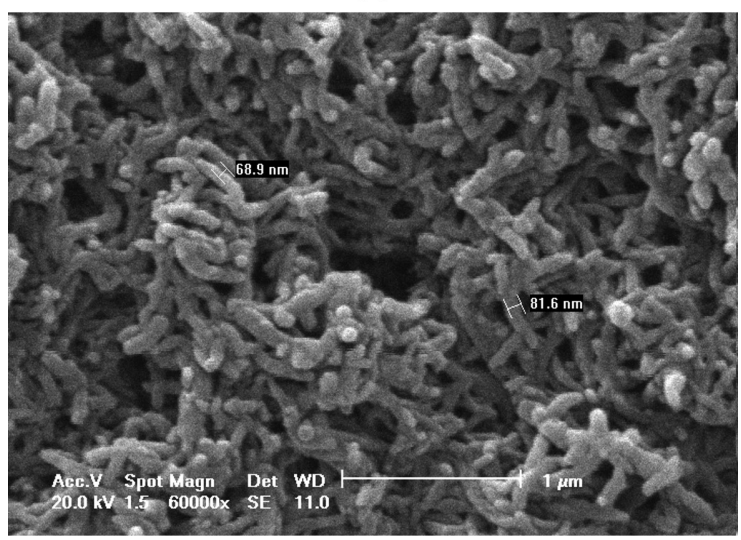

(b)

Figure 1. SEM of polyaniline nanofibers: (a) untreated polyaniline (b) treated polyaniline.

Table 1. Electrical properties of polyaniline nanofibers treated and untreated.

\begin{tabular}{lccc}
\hline \multicolumn{1}{c}{ Sample } & pH & Vacuum oven & $\begin{array}{c}\text { Electric Resistivity } \\
(\mathbf{\Omega . c m})\end{array}$ \\
\hline Untreated PAni & 2.0 & -- & 30.5 \\
Treated PAni & 4.0 & $\mathrm{~T}=80^{\circ} \mathrm{C}$, & 45.5 \\
& & 30 hours & \\
\hline
\end{tabular}

\subsection{Synthesis of PE/PAni composites}

The polyethylene and PAni nanofiber composites with different amounts of filler were obtained by in situ ethylene polymerization using the $\left[\mathrm{Cp}_{2} \mathrm{ZrCl}_{2}\right] / \mathrm{MAO}$ catalytic system. Disaggregation of the nanofibers in toluene by a sonication step was first required in order to achieve their good dispersion within the polyethylene matrix. Figure 2 highlights that the longer the sonication step, the more homogeneous will be the final composite morphology.

The influence of the experimental conditions (amount of PAni, ethylene pressure, and MAO quantity) on catalytic activity were evaluated in order to gain a better understanding of the process of polymerizing ethylene in the presence of Pani nanofibers. Table 2 presents the catalytic activity results in this process using the $\left[\mathrm{Cp}_{2} \mathrm{ZrCl}_{2}\right] / \mathrm{MAO}$ catalytic system.

The presence of PAni was found to increase the catalytic activity of the system, as seen in Table 2 under the evaluated conditions. However, an excess of PAni appears to lead to its decrease (samples 1, 2 and 6). Moreover, longer pre-contact between the PAni and MAO before polymerization would seem to have a positive influence on the catalytic activity

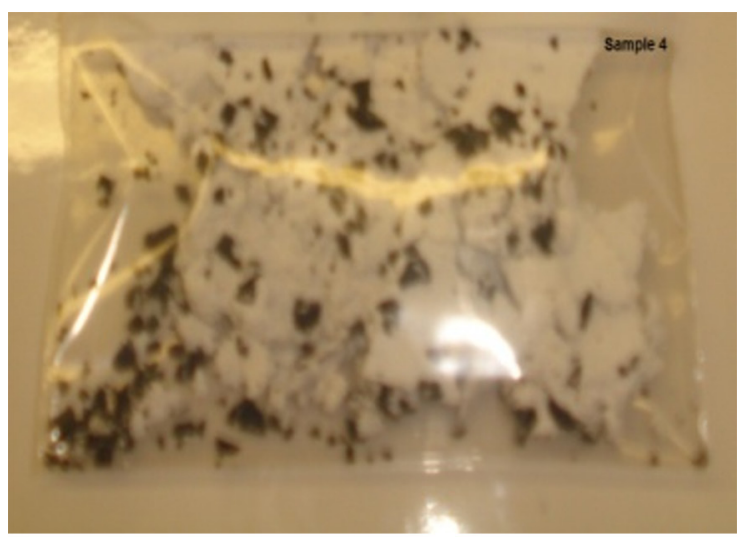

(a)

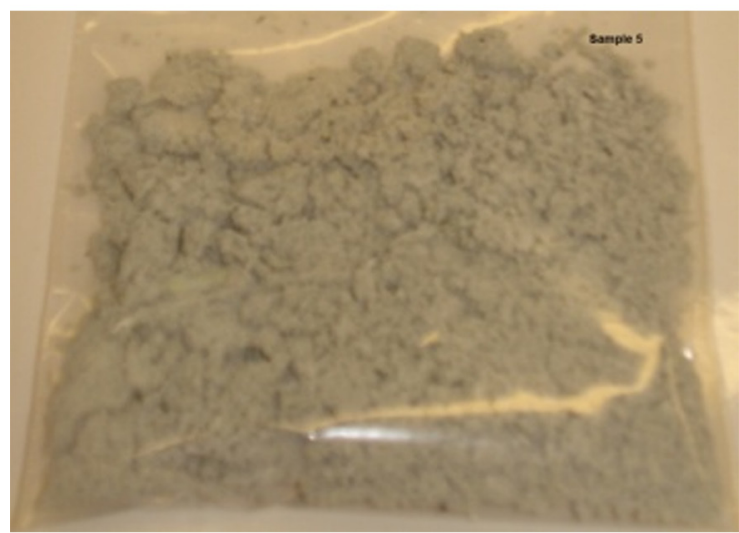

(b)

Figure 2. PE/PAni composites. Influence of sonication time of the nanofibers in toluene before polymerization: (a) 20 minutes (b) 60 minutes. 
Table 2. Catalytic activity in ethylene polymerization under different experimental conditions.

\begin{tabular}{ccccc}
\hline Sample & PAni (g) & Ethylene Pressure (bar) & MAO (mL) & $\begin{array}{c}\text { Catalytic Activity } \\
\text { (kgPE/molZr.h.bar) }\end{array}$ \\
\hline 1 & -- & 2.8 & 3.6 & 252.2 \\
2 & 0.25 & 2.8 & 3.6 & 1183.7 \\
$3^{\mathrm{a}}$ & 0.25 & 2.8 & 1.8 & 1307.3 \\
4 & 0.25 & 2.8 & 1.8 & 849.1 \\
5 & 0.25 & 2.0 & 3.6 & 1224.1 \\
6 & 0.50 & 2.8 & 3.6 & 507.8 \\
\hline
\end{tabular}

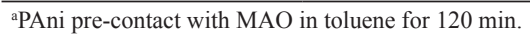

of the system (samples 3 and 4). A theory to explain such a result depends on the ability to generate interactions between the PAni and $\left[\mathrm{Cp}_{2} \mathrm{ZrCl}_{2}\right] / \mathrm{MAO}$. An electrochemical investigation was performed to further strengthen this idea and identify their nature, with the results described in the following section.

It is also noteworthy that the ethylene pressure had no significant influence on the catalytic activity (samples 2 and 5).

\subsection{Differential pulse voltammetry (DPV)}

Figure 3 (curve a) shows the differential pulse voltammogram with cathodic scan for the PAni-modified electrode, which exhibited a cathodic peak at $-1.35 \mathrm{~V}$. This polymer presented no sign when dispersed in the solution and not as part of the electrode composition. Consequently, it can be asserted that PAni is a conductor system.

Figure 3 (curve b) illustrates the cathodic signs to the metallocene complex $\left[(\mathrm{Cp})_{2} \mathrm{ZrCl}_{2}\right]$ used as a catalyst in the catalytic system PAni/[(Cp)2ZrCl2]/MAO. The differential pulse voltammogram illustrates cathodic signs at $-1.55 \mathrm{~V}$, $-1.75 \mathrm{~V}$ and $-2.0 \mathrm{~V}$, which were attributed to the redox process centered on the metallic ion ${ }^{11}$.

In order to understand curve $\mathrm{c}$ in Figure 3, it is necessary to evaluate the profile of the differential pulse voltammogram for $\left[(\mathrm{Cp})_{2} \mathrm{ZrCl}_{2}\right]$ with an anodic and cathodic sweep in Figure 4. Negative potentials show three redox pairs assigned to the reduction of zirconium (Figure 4 - curves $\mathrm{a}$ and $\mathrm{b}-1)$. Besides these peaks there is an irreversible anodic process at a positive potential that involves ligand oxidation (Figure 4 - curve b-2).

Taking into account the $\left[\mathrm{Cp}_{2} \mathrm{ZrCl}_{2}\right]$ data in Figure 3 (curve $b$ ), the pulse differential voltammetry profile in a cathodic scan of the PAni/ $\left[\mathrm{Cp}_{2} \mathrm{ZrCl}_{2}\right]$ modified electrode (Figure 3-curve c) shows the presence of a large sign in the $-1.5 \mathrm{~V}$ region, which is assigned to the reduction/ oxidation of zirconium with the contribution of PAni reduction (Figure 3 - curve b). Two additional reductions at a more negative potential with low current intensity were illustrated and are attributed to other reductions of the metallic center.

The differential pulse voltammogram in Figure 5 of $\left[(\mathrm{Cp})_{2} \mathrm{ZrCl}_{2}\right]$ in acetonitrile solutions in the presence of PAni illustrates a small shift of the cathodic peaks attributed to the reduction of $\mathrm{Zr}$, but the numbers of sign $\left[(\mathrm{Cp})_{2} \mathrm{ZrCl}_{2}\right]$ in acetonitrile solution with the absence of PAni are equal. This suggests similar stability for $\mathrm{Zr}(\mathrm{IV})$. These results

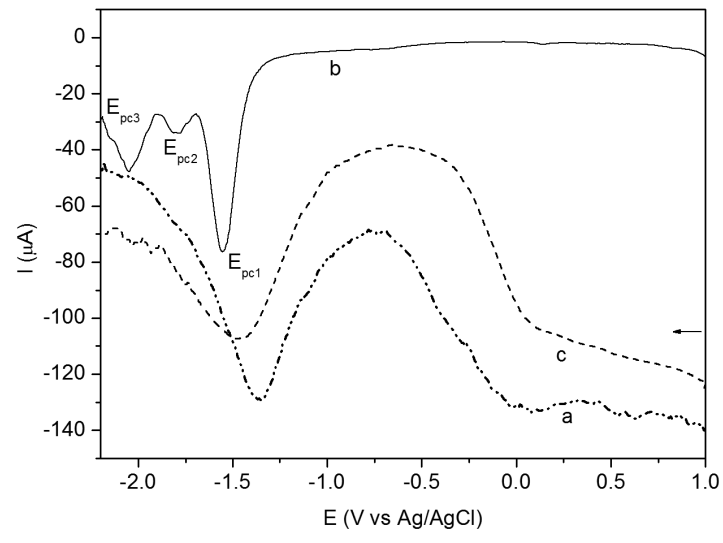

Figure 3. Differential pulse voltammograms - (a) polyaniline-modified electrode (b) $1 \times 10^{-3} \mathrm{~mol} \mathrm{~L}^{-1}\left[(\mathrm{Cp})_{2} \mathrm{ZrCl}_{2}\right]$ and (c) PANI/[(Cp) $\left.\mathrm{ZrCl}_{2}\right]-$ modified electrode. $\mathrm{v}=100 \mathrm{mV} \mathrm{s}^{-1}$.

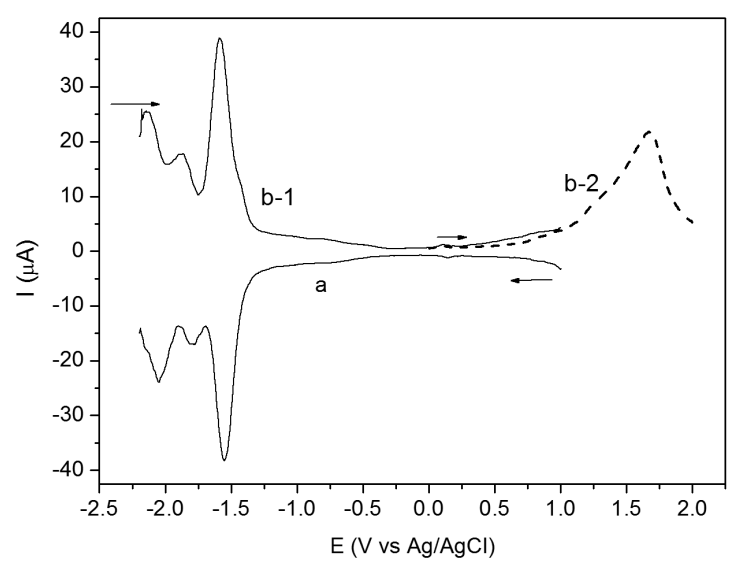

Figure 4. Differential pulse voltammograms of $1 \times 10^{-3} \mathrm{~mol}^{-\mathrm{L}^{-1}}$ $\left[(\mathrm{Cp})_{2} \mathrm{ZrCl}_{2}\right] \mathrm{v}=100 \mathrm{mV} \cdot \mathrm{s}^{-1}$. (a) cathodic scan and (b) anodic scan.

are consistent with a weak interaction between PAni and metallocene.

The electrochemical behavior of $\mathrm{PAni} /\left[\mathrm{Cp}_{2} \mathrm{ZrCl}_{2}\right]$ was also investigated in the presence of MAO. Figure 6 shows the DPV of $\left[\mathrm{Cp}_{2} \mathrm{ZrCl}_{2}\right]$ with amounts of MAO in a molar ratio $\mathrm{Al} / \mathrm{Zr}=3$ and 6 . The successive pulse voltammograms show that the current of the cathodic peak centered at $-1.5 \mathrm{~V}\left(\mathrm{E}_{\mathrm{pc} 1)}\right.$ disappeared and for $\mathrm{E}_{\mathrm{pc} 2}$ the intensity current 


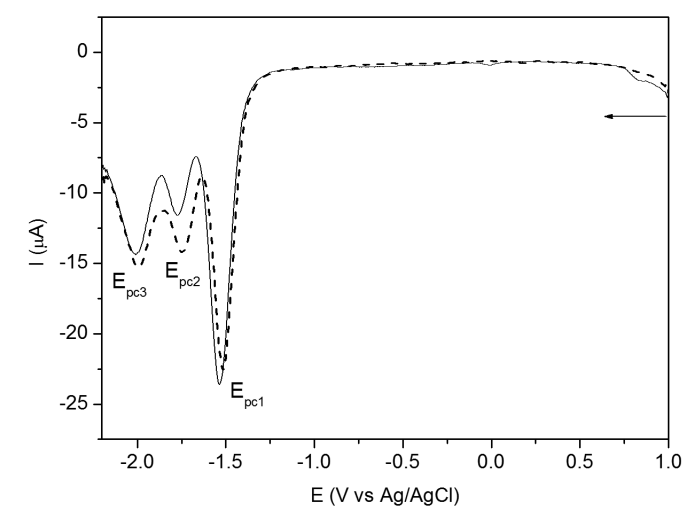

Figure 5. Differential pulse voltammograms of $1 \times 10^{-3} \mathrm{~mol}^{-1}$ $\left[\mathrm{Cp}_{2} \mathrm{ZrCl}_{2}\right] \mathrm{v}=100 \mathrm{mV} \cdot \mathrm{s}^{-1}$. Cathodic scan. Curve (solid): $\left[\mathrm{Cp}_{2} \mathrm{ZrCl}_{2}\right]$ in acetonitrile solution. Curve (dash): $\left[\mathrm{Cp}_{2} \mathrm{ZrCl}_{2}\right] / \mathrm{PANI}$ in acetonitrile solution.

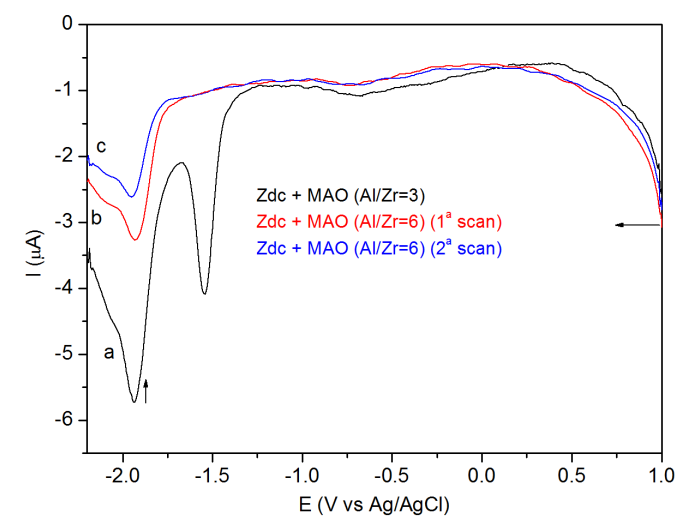

Figure 6. Differential of pulse voltammograms of $1 \times 10^{-3} \mathrm{~mol}^{-1}$ [ $\mathrm{Cp}_{2} \mathrm{ZrCl}_{2}$ ] with MAO. Al/MAO: 3 (a), 6 (b) (first scan), and (c) (second scan)). Cathodic scan. $\mathrm{v}=100 \mathrm{mV} \cdot \mathrm{s}^{-1}$.

decreased within time. Silveira and coworkers reported that this fact is related to the possible instability of the species containing the methyl group which is active in the polymerization reaction ${ }^{12}$. On the other hand, the DPV PAni/[ $\left[\mathrm{Cp}_{2} \mathrm{ZrCl}_{2}\right] / \mathrm{MAO}$ can be seen in Figure 7 in which the consumption of $\left[\mathrm{Cp}_{2} \mathrm{ZrCl}_{2}\right]$ for the formation of active species occurs in a longer period if compared to the absence of PAni (Figure 6), which is probably due to part of the consumption of MAO by PAni.

Therefore the increase of catalytic activity may be a kinetic consequence of the consumption of the active

\section{References}

1. Collier PCR, Backer GB and Branz LTD. The influence of construction detailing on the fire performance of polystyrene insulated panels. Fire Technology. 2013; 49(2):195-211. http:// dx.doi.org/10.1007/s10694-011-0238-5.

2. Xu Q, Ouyang J, Yang Y, Ito T and Kido J. Ultrahigh efficiency green polymer light-emitting diodes by nanoscale interface

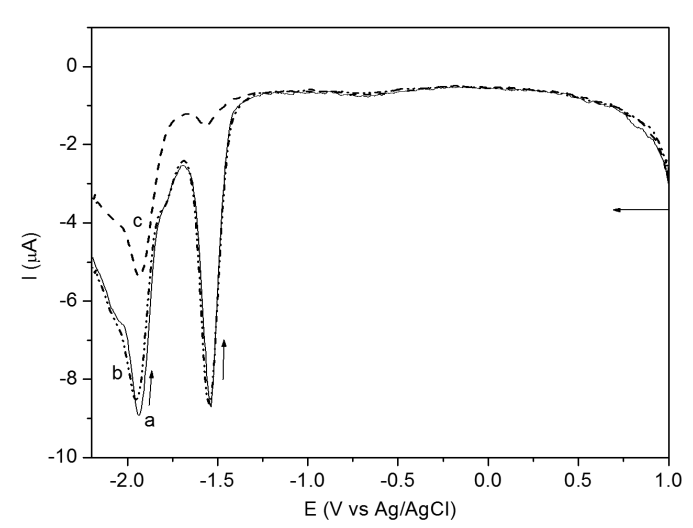

Figure 7. Differential of pulse voltammograms of $1 \times 10^{-3} \mathrm{~mol} \mathrm{~L}^{-1}$ $\left[(\mathrm{Cp})_{2} \mathrm{ZrCl}_{2}\right]$ with PAni/MAO. Al/Zr: 3 e $6 . \mathrm{v}=100 \mathrm{mV} \cdot \mathrm{s}^{-1}$. Cathodic scan (a) $\mathrm{Al} / \mathrm{Zr}=3$ (first scan), (b) $\mathrm{Al} / \mathrm{Zr}=3$ (second scan), (c) $\mathrm{Al} / \mathrm{Zr}=6$.

species, which is lower with the presence of PAni. However, an excess of PAni in the reaction medium may cause the MAO to become unavailable for the formation of the active species and thus diminish catalytic activity.

\section{Conclusions}

PAni nanofibers and polyethylene composites were prepared by in situ ethylene polymerization. Pretreatment for excess moisture and dopant removal did not significantly alter the morphology and electrical conductivity of the nanofibers. The catalytic activity of the $\mathrm{MAO} /\left[\mathrm{Cp}_{2} \mathrm{ZrCl}_{2}\right]$ system was notably affected by the amount of PAni nanofibers present in the reaction medium during the ethylene polymerization. Electrochemical study showed that catalytic alteration may be due to kinetic consumption of the active species, which occurs at a lower rate in the presence of polyaniline. The polymerization reaction step involving coordination of the ethylene to the metallic center of the active species is more favored as the PAni/ $\mathrm{Cp}_{2} \mathrm{ZrCl}_{2} / \mathrm{MAO}$ catalytically active species has a longer half-life, justifying the increased catalytic activity. This statement is based on the negligible change in the $\mathrm{Zr}^{\text {IV/III }}$ reduction potential of pure $\left[\mathrm{Cp}_{2} \mathrm{ZrCl}_{2}\right]$ and in the catalytic system in the presence of PAni.

\section{Acknowledgements}

This work was partially financed by CAPES, CNPQ and FAPERGS.

modification. Journal Applied Physics Letters. 2003; 83(23):46954697. http://dx.doi.org/10.1063/1.1630848.

3. Mattoso LHC. Polianilinas: síntese, estrutura e propriedades. Quimica Nova. 1996; 19(4):388-399.

4. Wan M. Conducting polymers with micro or nanometer structure. New York: Springer Science \& Business Media; 2008. 292 p.

5. Bhadra S, Khastgir D, Singha NK and Lee JHP. Progress in preparation, processing and applications of polyaniline. 
Progress in Polymer Science. 2009; 34(8):783-810. http:// dx.doi.org/10.1016/j.progpolymsci.2009.04.003.

6. Alexandre M, Pluta M, Dubois P and Jérôme R. Metallocene catalyzed polymerization of ethylene in the presence of graphite, 1 . Synthesis and characterization of the composites. Macromolecular Chemistry and Physics. 2001; 202(11):2239-2246. http:// dx.doi.org/10.1002/1521-3935(20010701)202:11<2239::AIDMACP2239>3.0.CO;2-8.

7. Fim FC, Guterres J, Basso NRS and Galland GB. Polyethylene/ graphite nanocomposites obtained by in situ polymerization. Journal of Polymer Science. Part A, Polymer Chemistry. 2010; 48(3):692-698. http://dx.doi.org/10.1002/pola.23822.

8. Basso NRS, Oliveira F, Graebin AP, Moura CS, Fim F. C., Galland GB, et al. Polyaniline nanofibers for in situ MAOcatalyzed polymerization of ethylene. Journal of Applied Polymer Science. 2014; 131(23):41197.

9. Basso NRS, Greco PP, Carone CLP, Livotto PR, Simplicio LMT, Rocha ZN, et al. Reactivity of zirconium and titanium alkoxides bidentade complexes on ethylene polymerization. Journal of Molecular Catalysis A Chemical. 2007; 267(12):129-136. http://dx.doi.org/10.1016/j.molcata.2006.11.027.

10. Gheno G, Basso NRS, Ceschi MA, Livotto PR, Nascimento AA, Rocha ZN, et al. Flavone complexes of Ti and $\mathrm{Zr}$ active in ethylene polymerization. Applied Catalysis A, General. 2013; 467:439-449. http://dx.doi.org/10.1016/j.apcata.2013.08.015.

11. Costa FG, Simplício LMT, Rocha ZN and Brandão ST. Study of catalytic species metallocene/MAO and metallocene/TMA by cyclic voltammetry. Journal of Molecular Catalysis $A$ Chemical. 2004; 211(1-2):67-72. http://dx.doi.org/10.1016/j. molcata.2003.10.027.

12. Silveira F, Simplicio LMT, Rocha ZN and Santos JHZ. Metallocenes in ethylene polymerization studied by cyclic and differential pulse voltammetry. Applied Catalysis A, General. 2008; 344(1-2):98-106. http://dx.doi.org/10.1016/j. apcata.2008.04.006.

13. Silveira F, Sá DN, Rocha ZN and Santos JHZ. Metallocene combinations in ethylene polymerization: a cyclic and differential pulse voltammetry. Macromolecular Reaction Engineering. 2008; 2(3):253-264. http://dx.doi.org/10.1002/mren.200800002.

14. Loukova GV. The first experimental approach to probing frontier orbitals and HOMO-LUMO gap in bent metallocenes. Chemical Physics Letters. 2002; 353(3-4):244-252. http:// dx.doi.org/10.1016/S0009-2614(02)00031-3.

15. Huang $J$ and Kaner RB. Nanofiber formation in the chemical polymerization of aniline: a mechanistic study. Angewandte Chemie. 2004; 43(43):5817-5821. http://dx.doi.org/10.1002/ anie.200460616. PMid:15523723.

16. Zhang D and Wang Y. Synthesis and applications of onedimensional nano-structured polyaniline: an overview. Materials Science and Engineering B. 2004; 134(1):9-19. http://dx.doi. org/10.1016/j.mseb.2006.07.037.

17. Sinha S, Bhadra S and Khastgir D. Effect of dopant type on the properties of polyaniline. Journal of Applied Polymer Science. 2009; 112(5):3135-3140. http://dx.doi.org/10.1002/app.29708. 